\section{ETESA, Esferas y STS}

\section{ETESA, spheres and STS}

\section{Sr. Editor:}

La Revista Médica de Chile publicó en su volumen 142, enero de 2014, un Suplemento dedicado a la Evaluación de Tecnologías Sanitarias. En una selección de 9 artículos, escritos por profesionales de la salud, ingenieros y economistas, se revisó la situación internacional y local respecto de "un proceso sistemático de valoración de las propiedades, los efectos y/o los impactos de la tecnología sanitaria", de acuerdo a la definición de la International Network of Agencies for Health Technology Assesment (INAHTA) citada en ${ }^{1}$ y se revisaron dimensiones e implicancias del mismo proceso.

Ese Suplemento y las consideraciones institucionales sobre tecnologías sanitarias, dan cuenta de la necesidad de pensar que la medicina actual ha devenido en una acción predominantemente técnica. La notable proliferación de objetos técnicos que pueblan el mundo de los enfermos, equipos, medicamentos, alternativas diagnósticas y terapéuticas, la cantidad de saber técnico sub especializado que es necesario convocar para decidir clínicamente, invitan a darle una mirada reflexiva.

Repensar la técnica es saludable y necesario. Lo que se propone en este Suplemento es uno de los posibles abordajes, marcado por lo sistemático y la perspectiva del formato económico de evaluación.

A esta opción, tomada por los editores del Suplemento, desearía adicionar al menos dos otras miradas que me parecen valiosas.

Una, de la filosofía, que ha pensado la técnica y sus efectos de una manera a veces difícil y hasta elusiva, pero no menos verdadera. Si Heidegger ha sido uno de los pensadores de la técnica², quizás es Peter Sloterdijk, uno de aquellos que ha pensado acerca de la técnica, con y contra el filósofo. Proponiendo una onto historia en que la técnica es el principal acto de producción de espacio y reflexividad, esta filosofía deja en mal pie a las interpretaciones pesimistas acerca de la técnica: "No hay motivo para no creer que lo mejor esté surgiendo ahora mismo o que lo traiga el futuro" (3, p. 255). Por el contrario, pone a la filosofía en la tarea de comprender el rol protésico de las máquinas. En diálogo con el trabajo de Michel Serres ${ }^{4}$, Sloterdijk nos anima a pensar la técnica como señal de la necesidad de ordenarnos en torno a un proceso cultural de diálogo y respeto, que denomina camino civilizatorio.

La segunda mirada que me parece necesaria, es la que procede de los estudios Science Technology and Society $(\mathrm{STS})^{5}$, reconociendo en Bruno Latour ${ }^{6,7}$ la figura más productiva de una heterogénea comunidad de investigadores. La cuestión aquí es cómo comprender sociológicamente la técnica, su papel como articulador de colectivos y la emergencia de nuevos problemas, allí donde nuevos actores (y “actantes", según la expresión acuñada por estos trabajos) pueblan nuestra vida.
Tanto Sloterdijk como los estudios STS, han abordado cuestiones del mundo de la salud y la técnica, incluyendo un abordaje sociológico de la construcción de mercados y economías.

Si el gobierno que terminó su mandato en 2014, habiendo llegado a una convicción de la importancia de estudiar la técnica en la clínica, implementó una estructura ministerial a tal efecto, también valdría la pena esforzarnos en constituirla con una comprensión plural y diversa, incluyendo estilos de pensamiento como la filosofía y la sociología. Con seguridad ni la una ni la otra son lujos. Al contrario, ignorarlas sería una irresponsabilidad que no podemos permitirnos.

El logos de la técnica es mucho más que la economía. Hay en el interior de la técnica más saber que las métricas de mercado. Las aproximaciones basadas en la mensura económica y en la reducción de costos, suponen un mundo regido por leyes naturales y hechos incontrovertidos, ya caducos.

Una de las más importantes lecciones de la técni$\mathrm{ca}$, es el sorprendente predominio de lo artificial en nuestras vidas. $\mathrm{Y}$, a la vez, sin artificios intelectuales no hay comprensión de la artificialidad del presente. Lo que necesitamos es la invención de nuevas ideas para comprender una actualidad, que constantemente nos rebasa. Tarea que no merece excluidos, porque el saber es un proceso plural, colectivo y democrático. $\mathrm{Si}$ alguien no lo sabe, la historia de la técnica puede volver a enseñárnoslo.

Yuri Carvajal

Escuela de Salud Pública, Facultad de Medicina, Universidad de Chile.

\section{Referencias}

1. Kuhn-Barrientos L. Evaluación de Tecnologías Sanitarias: marco conceptual y perspectiva global. Rev Med Chile 2012; 142 (S1): S11-15.

2. Heidegger M. Filosofía, ciencia y técnica. Santiago, Chile: Editorial Universitaria; 2007, quinta edición.

3. Sloterdijk P. Sin salvación. Tras las huellas de Heidegger. Madrid, España: akal; 2011.

4. Serres M. Pulgarcita. El mundo cambió tanto que los jóvenes deben reinventar todo: una manera de vivir juntos, instituciones, una manera de ser y conocer... Buenos Aires, Argentina: Fondo de Cultura Económica; 2013.

5. Hackett E, Amsterdamska, Lynch M, Wajcman J (eds). The Handbook of Science and Technology Studies. London, England; The MIT Press; 2008.

6. Latour B. Cogitamus. Seis cartas sobre las humanidades científicas. Buenos Aires, Argentina: Paidós; 2012.

7. Latour B. Aramis ou l'amour des techniques. Paris, France: éditions la découverte: 1992.

Correspondencia a:

Dr. Yuri Carvajal

ycarvajal@med.uchile.cl 